\title{
Experimental and Theoretical Investigation on a Solar Chimney System for Ventilation of a Living Room
}

\author{
Billal Belfegas ${ }^{1}$, Salah Larbi $^{1}$, Tahar Tayebi $^{2 *}$ \\ ${ }^{1}$ Mechanical Engineering and Development Laboratory, National Polytechnic School, Algiers 1, 10, Avenue Hassen Badi, \\ Algiers 16200, Algeria \\ ${ }^{2}$ Department of Mechanical Engineering, Faculty of Sciences and Technology, Mohamed El Bachir El Ibrahimi University, \\ Bordj Bou Arreridj, El-Anasser 34030, Algeria
}

Corresponding Author Email: t.tayebi@univ-bba.dz

https://doi.org/10.18280/mmep.080213

Received: 27 March 2020

Accepted: 2 January 2021

\section{Keywords:}

solar chimney, energy performances, passive ventilation, experimental study, numerical simulation

\begin{abstract}
The present work relates to the analysis of an energy system based on the solar chimney for passive ventilation of a living space. It consists of an experimental and theoretical study of the energy performance according to some geometrical and environmental parameters. The designed prototype was installed and followed for several days. In parallel, a numerical code was developed in FORTRAN platform to simulate the phenomena in the solar chimney and compare the theoretical results with those experimental in the transient regime. The results obtained relate to the distributions of temperature on the glazing, within the airflow and on the internal wall of the chimney. The hourly rate of air change $(\mathrm{ACH})$, the air-outlet velocity and its mass flow rate have also been determined. The comparison of the results obtained in this study with those of the literature has shown a good agreement. The obtained results have shown that the incidental solar radiation plays a fundamental role in the energy performance of such systems and there is an optimum value of the ratio between the width of the chimney and the wall opening for a high rate of air renewal.
\end{abstract}

\section{INTRODUCTION}

In the architecture of classical buildings in the Mediterranean or tropical regions, the use of passive ventilation by large openings to preserve appropriate thermal comfort is a well-known and old concept. In temperate climates where the architecture is generally not designed for hot climatic conditions, the use of natural ventilation is seasonal and it's done at the initiative of the occupants by their action on the ventilation openings. Mechanical ventilation systems have undesirable energy involvement as they further require operating electricity. For some cities, air conditioning requirements use almost the full capacity of their electricity grids [1]. Also, mechanical ventilation systems are related to high carbon emission, which has a negative impact on the environment. On the other hand, natural ventilation is expected to provide cooling energy savings of approximately $10 \%$ and provide annual energy consumption of $15 \%$ when climate operating conditions are appropriate [2].

Therefore, natural ventilation is being offered as a means of saving energy and providing adequate thermal air quality for inhabitants inside the buildings as well as for offices and industrial spaces. Natural ventilation is generated by thermal buoyancy forces which creates pressure differences for the airflow (or wind) [3].

The solar chimney system is an excellent example, as it was designed to increase the effect of ventilation by increasing the solar gain [4], thus creating an adequate temperature difference between the inside and outside of the building to drive adequate airflow. The solar chimney is a thermo- syphonic air channel in which the main driving mechanism of air circulation is natural convection [5]. There are different configurations of solar chimney design, which are affected by multiple criteria such as location, climate, size of the space to be ventilated, and indoor heat gain [6]. However, basic elements such as solar collectors, clear cover, and openings are part of each design.

The first fundamental study on the solar chimney was performed by Bansal et al. [3]. The study is analysis of the improvement of ventilation in living spaces by using a solar chimney. The authors have developed steady-state equations to model chimney heat transfer processes. They found that the ventilation rates obtained vary between 140 and $330 \mathrm{~m}^{3} / \mathrm{h}$, for solar radiation varying from 220 to $1000 \mathrm{~W} / \mathrm{m}^{2}$. Several theoretical and experimental research projects followed those of Bansal et al. [3]. These studies are mainly aimed to improve the energy performance of the solar chimney systems [4-32]. For illustration, Afonso and Oliveira [7] have showed the importance of thermal storage in chimneys. They reported that solar-assisted efficiency will be reduced by more than $60 \%$ if insulation is not provided on the outside of the brick wall of a solar chimney. It was mentioned that the optimum storage thickness for solar chimney depends on building use patterns. A small thickness was recommended for daytime ventilation, whereas, the greater thickness was suggested for night-time ventilation. An insulation thickness of $5 \mathrm{~cm}$ was considered optimum. Nouanégué et al. [8] numerically examined the idea of solar wind tower ventilation. They considered the mixed ventilation case: forced convection in a tower system resulting from negative pressure created at the tower outlet by the 
venture effect and natural convection due to the buoyancy effect. The Nusselt number and dimensionless volume flow rate were calculated as a function of the dimensionless conductivity of the solid medium, the Rayleigh number, the Reynolds number (or Richardson number) and geometric parameters such as aspect ratio, exit port size, and wall thickness. The result revealed that the wall thickness has a minor degree of influence on ventilation performance than the other parameters. Bassiouny and Koura [9] developed a correlation for the absorber average temperature and the average air exit velocity as a function of solar intensity. They suggested that the maximum absorber temperature could increase by a factor of 2.25 when the solar intensity increased by a factor of 5. Haghighi and Maerefat [10] examined the capability of a solar chimney to reach the required thermal and ventilation needs of individuals on winter days. In their analysis, the heat transfer by natural convection and surface radiation in a $2 \mathrm{D}$ vented room in contact with a cold external ambient is studied numerically. The dependence of the system performance on air gap depth of the solar chimney, size of openings, outdoor air temperature, and solar radiation have been investigated to determine the appropriate operating conditions and thermal comfort criteria. The findings show that the system is able to provide good indoor air conditions during the daytime; even with a poor solar intensity of 215 $\mathrm{W} / \mathrm{m}^{2}$ and a low ambient temperature of $5^{\circ} \mathrm{C}$. Imran et al. [11] experimentally and numerically studied the performance of a solar chimney. The steady two-dimensional turbulent flow model is proposed. The results showed that for solar intensity between 150 and $750 \mathrm{~W} / \mathrm{m}^{2}, 4-35$ air changes per hour were provided, and the airflow went rises by increasing the air gap. The purpose of Hosien et al. [12] is to investigate the performance of solar chimney used for natural ventilation of closed enclosure in order to save energy. To achieve this purpose, a mathematical model simulating the performance of solar chimney was developed. It's developed a computer program to solve the governing conservation equations. The results showed that the air change rate per hour $(\mathrm{ACH})$ was significantly dependent on the wind speed as well as the dimensions (height, gap, and width). The effect of chimney height was not significant enough to be cost-effective. It's showed that the air change rate per hour $(\mathrm{ACH})$ throughout the year was more than the desired ventilation standards in the enclosure space. Khanal and Lei [13] performed a numerical simulation of flow behavior due to natural convection of air inside a solar chimney with an imposed heat flux on a vertical absorber wall. Three distinct flow regimes are identified.

It appears from the literature review of the previous works that the performance of the solar chimney used for natural ventilation depends mainly on two groups of parameters. One is the geometrical parameters such as chimney height, width, and gap, while the other is the operational parameters such as solar radiation, wind speed, and ambient temperature, etc. However, there is a lack of information about using other materials as an external wall (glazing cover) for the chimney, this is because the previous researches have been chiefly concerned with using glass as an external cover. Moreover, little attention has been given to study the influence of wind speed on the performance of the solar chimney.

The present work relates to an experimental and numerical study of a solar chimney under Algerian climatic conditions. The energy performance of the chimney according to the geometrical and environmental parameters will be determined experimentally and numerically. An in-house FORTRAN code is developed for the numerical solution. Effects of incidental solar radiation on the instant temperature distributions in different components, the mass flow of air circulation inside the chimney, the Air Changes Per Hour $(\mathrm{ACH})$, and the efficiency are examined.

The schematic representation of the solar chimney is given in Figure 1.

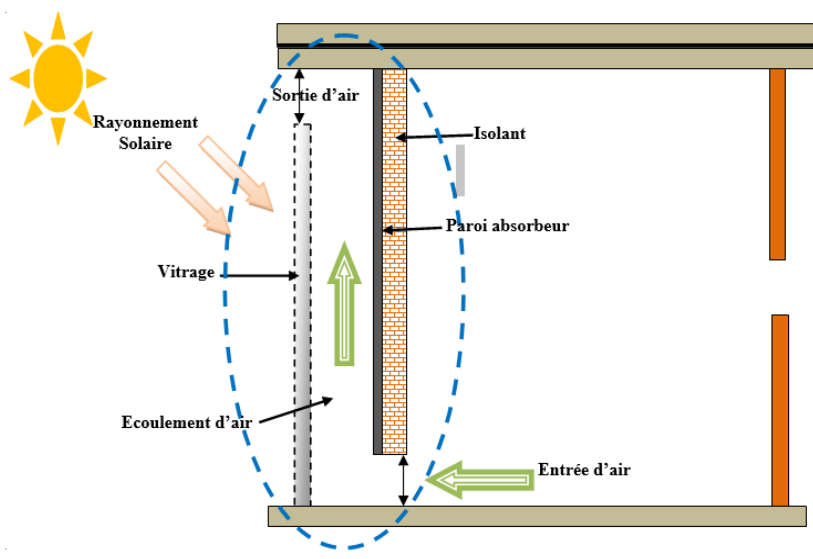

Figure 1. Schematic representation of the solar chimney passive ventilation system

\section{EXPERIMENTAL SETUP}

The experimental installation developed is shown in Figure 2. A room of $1 \mathrm{~m} \times 1 \mathrm{~m} \times 1 \mathrm{~m}$ was constructed using the "B13" panel. The solar chimney is installed on the south wall of this room. It consists of an absorbent wall, $1 \mathrm{~mm}$ sheet steel, glued and painted with matte black paint, and the second built by the thermic with a thickness of $5 \mathrm{~mm}$. The side of the chimney is covered by $3 \mathrm{~mm}$ thick glass panel; the dimensions of the solar chimney are $1 \mathrm{~m}$ long, $40 \mathrm{~cm}$ wide with three input thicknesses, namely: $10 \mathrm{~cm}, 20 \mathrm{~cm}$, and $30 \mathrm{~cm} .12$ thermometers were installed at different points on the solar chimney for temperature measurement. Three thermometers for measuring the temperature of the absorber wall, three thermometers for measuring the air temperature inside the solar chimney, three thermometers for measuring the glass temperature and two thermometers for measuring input and output air temperatures in the room and one for measuring the ambient temperature. The thermometers were connected to an acquisition card. The wind speed was measured using an anemometer. The solar radiation was measured by a solar Pyranometer having a minimum value of $0.1 \mathrm{~W} / \mathrm{m}^{2}$ and an accuracy of $\pm 1 \%$ (Figure $3)$.

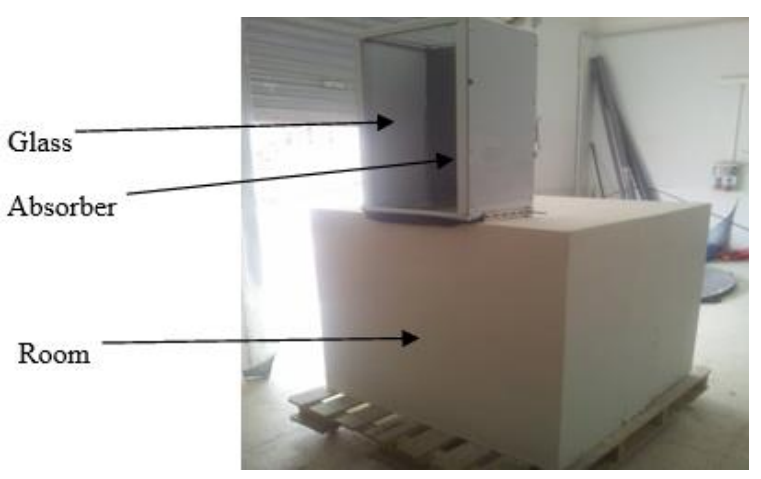

Figure 2. Experimental solar chimney 


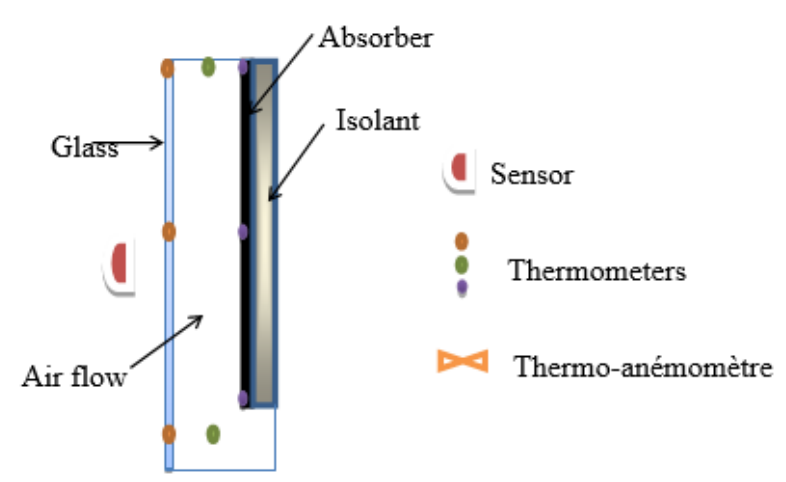

Figure 3. Placement of the sensors in the solar chimney

\section{MATHEMATICAL MODELING}

Figure 4 shows the physical model used in this study, which consists of a solar chimney with an air inlet by its opening lower than an intake temperature, $T f_{\text {, }}$, assumed equal to the temperature of the room, $T r$. The hot air flows through the chimney top at an outlet temperature $T f_{, 0}$. The walls of the chimney consist of the glazing on the left side and the absorber on the right side.

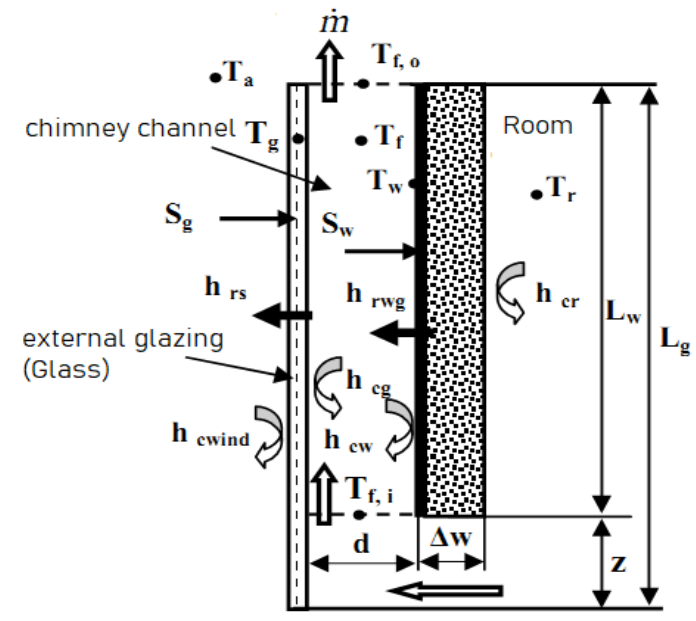

Figure 4. Physical model used

The mathematical model is based on equations of thermal balances at the glazing, the absorbent wall and along the chimney channel. The basic assumptions used are: the inlet air temperature in the chimney is assumed to be uniform and equal to that of the room; the surface temperatures of the absorber and the glazing are supposed to be uniform; the air frictions forces at the walls of the chimney are supposed to be negligible compared to the air pressure forces generated by the thermal gradient; the storage capacities of the glazing and the absorber are supposed to be negligible.

The corresponding equations are:

$$
\begin{gathered}
\rho_{g} V_{g} C p_{g} \frac{\partial T_{g}}{\partial t}=S_{1} A_{g}+U_{t} A_{g}\left(T_{a}-T_{g}\right) \\
+h_{g} A_{g}\left(T_{f}-T_{g}\right)+A_{w}\left(T_{w}-T_{g}\right) \\
\rho_{f} V_{f} C p_{f} \frac{\partial T_{f}}{\partial t}+q^{\prime \prime} \\
=h_{g} A_{g}\left(T_{g}-T_{f}\right)+h_{w} A_{w}\left(T_{w}-T_{f}\right)
\end{gathered}
$$

$$
\begin{gathered}
\rho_{w} V_{w} C p_{w} \frac{\partial T_{w}}{\partial t}=S_{2} A_{w}+U_{b} A_{w} T_{r}+h_{r w g} A_{w} T_{g} \\
+h_{w} A_{w} T_{f}-\left(h_{w}+h_{r w g}+U_{b}\right) A_{w} T_{w}
\end{gathered}
$$

where: $U_{t}$ is the overall exchange coefficient between the glazing and the atmosphere, given by:

$$
U_{t}=h w_{\text {ind }}+h_{r s}
$$

The convective heat transfer coefficient, $h_{\text {Wind }}$, is relative to the environment. It's given by the expression $[14,15]$ :

$$
h_{\text {Wind }}=2.8+3 V_{w}
$$

where: $V_{w}$, is the air ambient wind speed.

The radiative heat transfer coefficient, $h_{r s}$ between the surface of the glass and the sky is expressed by:

$$
h_{r s}=\frac{\sigma \varepsilon_{g}\left(T_{g}+T_{s}\right)\left(T_{g}^{2}+T_{s}^{2}\right)\left(T_{g}-T_{s}\right)}{\left(T_{g}-T_{a}\right)}
$$

The temperature of the sky, $T_{s}$, is expressed by:

$$
T_{s}=0.0552 T_{a}^{1.5}
$$

The solar radiation absorbed by the glazing is given by:

$$
S_{1}=\alpha_{1} H
$$

The radiative heat transfer coefficient, $h_{r w g}$, between the absorber and the glazing is expressed by:

$$
h_{r w g}=\frac{\sigma\left(T_{g}^{2}+T_{w}^{2}\right)\left(T_{g}-T_{w}\right)}{\left(\frac{1}{\varepsilon_{g}}+\frac{1}{\varepsilon_{w}}-1\right)}
$$

The convective heat transfer coefficient, $h_{g}$, between the glazing and the air of the channel is given by [14]:

$$
h_{g}=\frac{N u K_{f}}{L_{g}}
$$

with: $N u=0.60\left(G_{r} \times P_{r} \times \cos \theta\right)^{0.2}$ and $G_{r}=g \beta_{f} \Delta T L_{g}{ }^{3} / v_{f}^{2}$.

The thermal conductivity of the air is given by:

$$
K_{f}=0.00263+0.000074\left(T_{f}-300\right)
$$

The useful gain of heat can be calculated by:

$$
q^{\prime \prime}=\dot{m} C_{p, a}\left(T_{f, 0}-T_{f, i}\right)
$$

where: $\dot{m}$ and $C_{p, a}$, respectively denote the mass flow rate and the specific heat of the air.

The average temperature of the air flowing in the chimney is:

$$
T_{f}=\gamma T_{f, 0}+(1-\gamma) T_{f, i}
$$

The coefficient $\gamma$ is determined experimentally [14, 26]; it's equal to 0.74 . In addition, the temperature $T_{f, i}$ was taken equal to the ambient temperature, $T_{r}$. From where: 


$$
q^{\prime \prime}=\frac{\dot{m} C_{p, a}\left(T_{f}-T_{r}\right)}{\gamma}
$$

The mass flow of air in the chimney [3] is given by the expression:

$$
\dot{m}=C_{d} \frac{\rho_{f, 0} A_{0}}{\sqrt{\left(1+A_{r}\right)}} \sqrt{\frac{2 g L\left(T_{f}-T_{r}\right)}{T_{r}}}
$$
$15]$.

The value of the coefficient $C_{d}$ is taken equal to $0.57[3,14$,

The convective heat transfer coefficient between the absorber wall and the air channel is:

$$
h_{w}=\frac{N u \cdot K_{f}}{L_{W}}
$$

The dynamic viscosity of the fluid is expressed by:

$$
\mu_{f}=\left[1.846+0.00472\left(T_{f}-300\right)\right] \cdot 10^{-5}
$$

The mass density of the fluid is:

$$
\rho_{f}=1.1614-0.00353\left(T_{f}-300\right)
$$

The specific heat of the fluid is given by:

$$
C_{p, a}=\left[1.007+0.00004\left(T_{f}-300\right)\right] \times 10^{3}
$$

The coefficient of volume expansion in the air channel is expressed by:

$$
\beta=1 / T_{f}
$$

The overall exchange coefficient of the insulating board, located on the back part of the absorbent wall is expressed by:

$$
U_{b}=\frac{K_{i n s}}{\Delta w_{i n s}}
$$

The radiative flux absorbed by the absorbent wall is:

$$
S_{2}=\alpha_{2} H
$$

The airflow velocity in the chimney is expressed by:

$$
v_{0}=\frac{\dot{m}}{\rho_{f} A_{0}}
$$
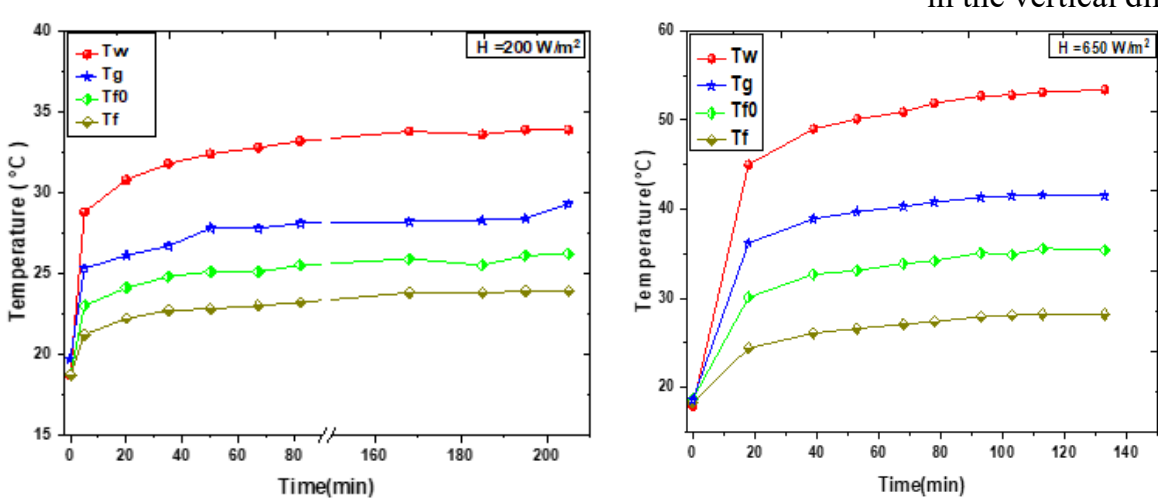

$$
A C H=\frac{Q_{V} \times 3600}{\text { Total volume of the room }}
$$

\section{RESULTS AND DISCUSSIONS}

The temperatures' distributions $T_{g}, T_{w}$ and $T_{f}$ on the glazing, the absorber et al.ong the air channel, respectively, as well as the mass flow of air in the chimney, the hourly rate of renewal of air in the room and efficiency as a function of time are determined experimentally and theoretically by means of the numerical resolution of the equations (1), (2) and (3) using the Gauss-Seidel method with relaxation coefficients for different solar irradiations.

\subsection{Experimental results}

Figure 5 shows respectively the experimental average temperatures distributions of the glazing, the absorber and along the air channel for $H=200 \mathrm{~W} / \mathrm{m}^{2}, H=650 \mathrm{~W} / \mathrm{m}^{2}$ and $H$ $=1,000 \mathrm{~W} / \mathrm{m}^{2}$. We notice at first glance that all temperatures profiles starting from the ambient temperature value to reach their maximum values and then remain stable over time. It's also underlined that the temperature of the absorber is higher than that of air and glazing, which is predictable, the absorption of the thermal radiation raises the temperature of the absorber wall and contributes to the increase of the temperature of the air in contact with these walls. In addition, the more solar radiation is important the more the temperature difference between these three components is important.

In Figure 6 we show the variation of the mass flow, the air changed per hour $(\mathrm{ACH})$ in the room and the efficiency as a function of different solar radiation. The curves have the same shape as those of the temperatures in Figure 5. We note that values of these quantities that correspond to $1,000 \mathrm{~W} / \mathrm{m}^{2}$ are always higher than those obtained with the other two low intensities. As the solar radiation intensity increases, the mass flow and efficiency increase. This phenomenon of natural convection is related to considerations of dynamic acceleration in the vertical direction corresponding to the buoyancy forces.

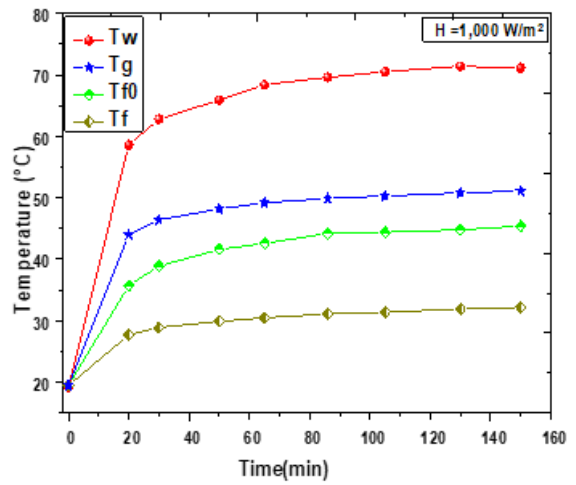

Figure 5. Evolution of the average experimental temperatures of the glazing, the absorber et al.ong the air channel as a function of time at $\mathrm{H}=200,650$ and $1,000 \mathrm{~W} / \mathrm{m}^{2}$ 

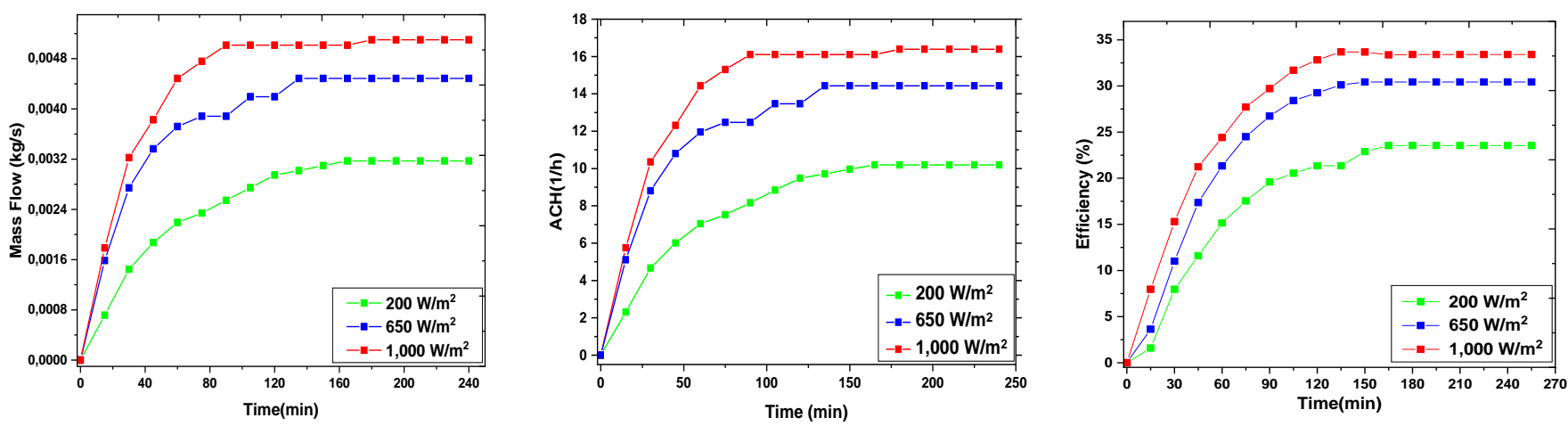

Figure 6. Evolution of the average experimental mass flow, $\mathrm{ACH}$ and efficiency as a function time for $\mathrm{H}=200,650$ and 1,000 $\mathrm{W} / \mathrm{m}^{2}$

\subsection{Theoretical results}

Figure 7 illustrates theoretical average temperatures distributions of the glass, the absorber and along the air channel for $\mathrm{H}=200 \mathrm{~W} / \mathrm{m}^{2}, \mathrm{H}=650 \mathrm{~W} / \mathrm{m}^{2}$ and $\mathrm{H}=1,000 \mathrm{~W} / \mathrm{m}^{2}$. The results show that the different temperatures are strongly dependent on the solar intensity. According to the figures, we note that the measured and calculated temperatures have the same profiles which illustrates the validity of the numerical model. It should be noted that the values of the temperature of different components increase by increasing the solar intensity and the gap between these temperatures also increases with the solar intensity.

Figure 8 presents the theoretical variation of the mass flow, the air changed by hour (ACH) as well as the efficiency as a function of time for different solar flux intensity. It can be seen from these profiles that the maximum values of flow rate, $\mathrm{ACH}$ and efficiency are achieved for higher solar irradiation $\left(1,000 \mathrm{~W} / \mathrm{m}^{2}\right)$
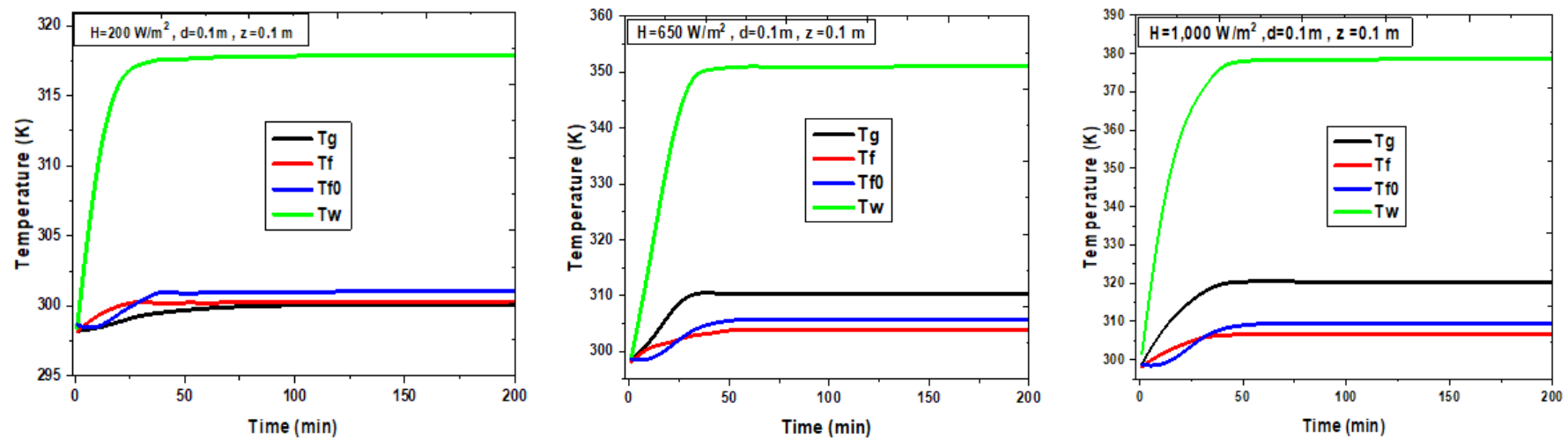

Figure 7. Evolution of the average theoretical temperatures of the glazing, the absorber et al.ong the air channel as a function of time for $\mathrm{H}=200,650$ and $1,000 \mathrm{~W} / \mathrm{m}^{2}$
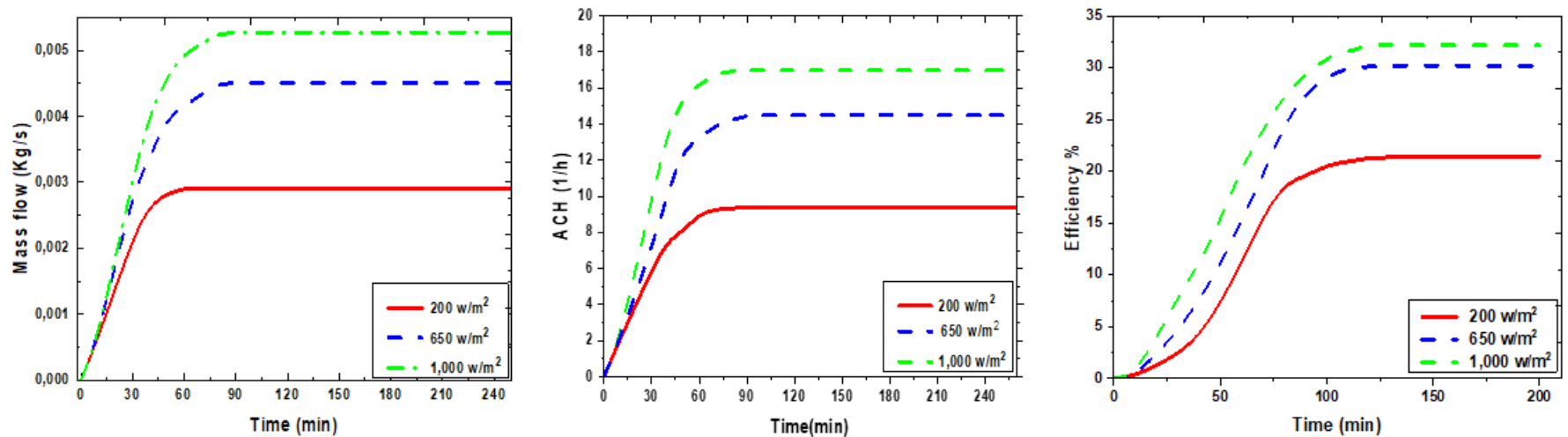

Figure 8. Theoretical evolutions of mass flow, $\mathrm{ACH}$ and efficiency as a function time for $\mathrm{H}=200,650$ and $1000 \mathrm{~W} / \mathrm{m}^{2}$

\section{VALIDATION}

Figures 9 and 10 show the evolutions of the average theoretical temperatures of the different elements of the chimney obtained by our code and those obtained by Ong and
Chow [14] as a function of chimney width for $\mathrm{H}=200 \mathrm{~W} / \mathrm{m}^{2}$ and $\mathrm{H}=650 \mathrm{~W} / \mathrm{m}^{2}$. It is noted at first sight that the temperature profiles are little influenced by the width of the chimney. A good agreement is observed between our obtained results and those of Ong and Chow [14]. As an indication, for a solar 
intensity of $200 \mathrm{~W} / \mathrm{m}^{2}$, the average absorber wall temperature is about $45.5^{\circ} \mathrm{C}$ for our model and it is $45^{\circ} \mathrm{C}$ for Ong and Ong and Chow [14]. And we have registered $75^{\circ} \mathrm{C}$ at $\mathrm{H}=650 \mathrm{~W} / \mathrm{m}^{2}$, while it is $76^{\circ} \mathrm{C}$ for Ong and Chow et al. [14]. It should also be emphasized that the temperature of the absorber and higher than that of air flowing in the chimney and glazing, which is predictable. In fact, the absorption of thermal radiation raises the temperature of the absorber wall and contributes to the elevation of the temperature of the air in contact with these walls.

In addition, Table 1 shows that the temperatures of the different elements of the chimney and the air speed at the outlet are proportional to the solar intensity. A good agreement between the results obtained and these obtained by Ong and Chow [14].
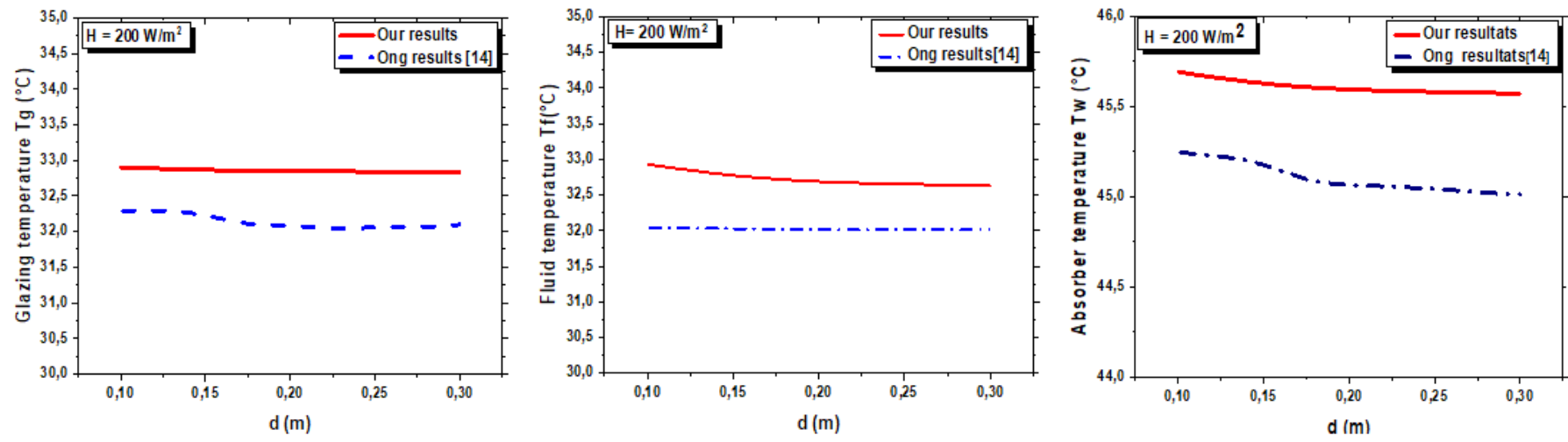

Figure 9. Comparison of the average theoretical temperatures of the different elements of the chimney with those obtained by Ong and Chow [14] as a function of chimney width at $\mathrm{H}=200 \mathrm{w} / \mathrm{m}^{2}$
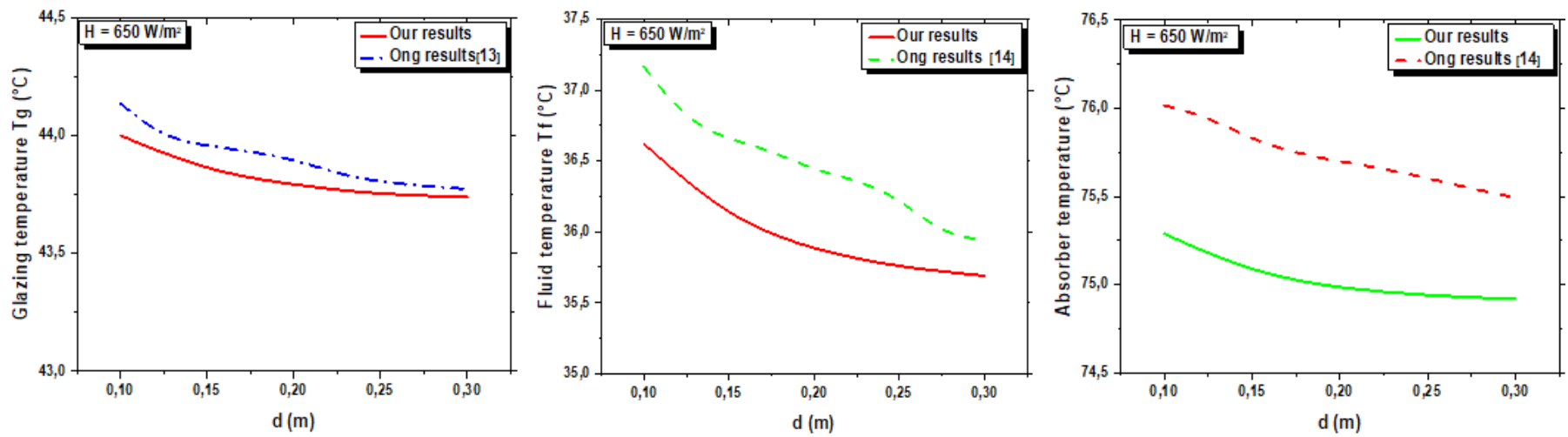

Figure 10. Comparison of the average theoretical temperatures of the different elements of the chimney with those obtained by Ong and Chow [14] as a function of chimney width at $\mathrm{H}=650 \mathrm{w} / \mathrm{m}^{2}$

Table 1. Comparison of our numerical and experimental results with these of Ong and Chow [14]

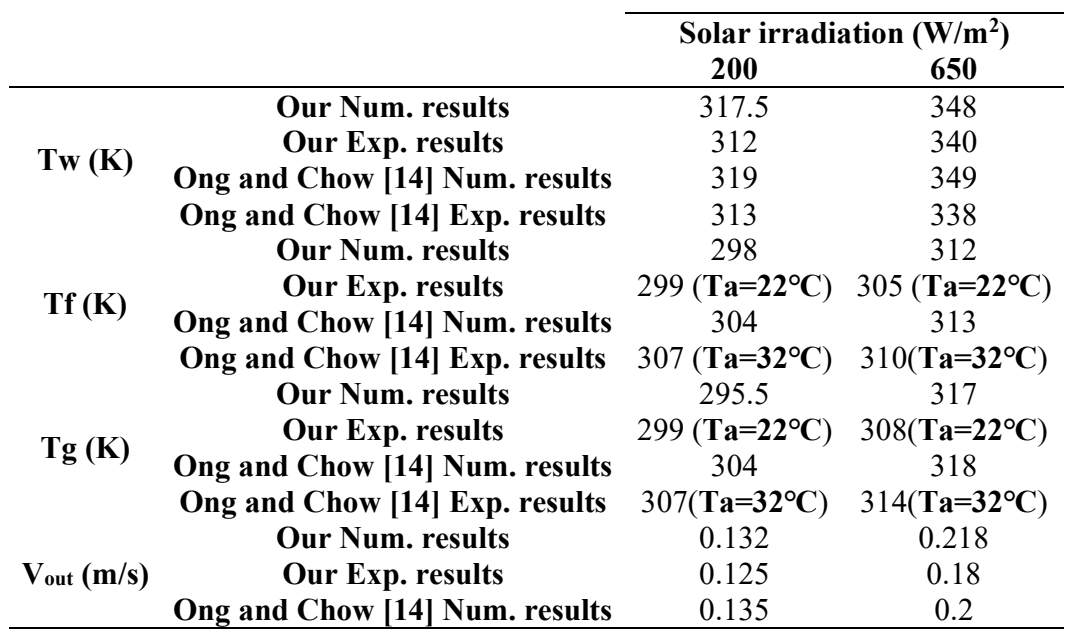

\section{CONCLUSION}

The main motivation of this work was to evaluate the behavior of a solar chimney adapted to construction and its thermal performance on the interior of the habitat. In order to accomplish the desired objective, a solar chimney prototype 
was designed, installed and tracked for several days. A mathematical model based on equations of the thermal balances of the different components of the solar chimney was also proposed. The solution of the resulting equations is established using the Gauss-Seidel method with relaxation factors. The comparison of our obtained results with those from the literature revealed a good agreement. The key conclusions of this study are as follows: the air temperature in the solar chimney depends significantly on the strength of the solar radiation. In addition, the air velocity at the outlet of the solar chimney increases with the rise of the intensity of the solar irradiation, this increases the ventilation process within the room indicating an enhanced in the thermal performance of the device considered. Moreover, the obtained results have shown that there is an optimum value of the ratio between the width of the chimney and the wall opening for a high rate of air renewal.

\section{REFERENCES}

[1] Linden, P.F. (1999). The fluid mechanics of natural ventilation. Annual Review of Fluid Mechanics, 31(1): 201-238. https://doi.org/10.1146/annurev.fluid.31.1.201

[2] Emmerich, S., Dols, W., Axley, J. (2001). Natural ventilation review and plan for design and analysis tools. NIST Interagency/Internal Report (NISTIR), National Institute of Standards and Technology, Gaithersburg, MD.

https://tsapps.nist.gov/publication/get_pdf.cfm?pub_id= 860854

[3] Bansal, N.K., Mathur, R., Bhandari, M.S. (1993). Solar chimney for enhanced stack ventilation. Building and Environment, 28(3): 373-377. https://doi.org/10.1016/0360-1323(93)90042-2

[4] Nikas, K.S., Nikolopoulos, N., Nikolopoulos, A. (2010). Numerical study of a naturally cross-ventilated building. Energy and Buildings, 42(4): 422-434. https://doi.org/10.1016/j.enbuild.2009.10.010

[5] Gan, G. (2006). Simulation of buoyancy-induced flow in open cavities for natural ventilation. Energy and Buildings, $\quad 38(5)$ : 410-420. https://doi.org/10.1016/j.enbuild.2005.08.002

[6] Harris, D.J., Helwig, N. (2007). Solar chimney and building ventilation. Applied Energy, 84(2): 135-146. https://doi.org/10.1016/j.apenergy.2006.07.001

[7] Afonso, C., Oliveira, A. (2000). Solar chimneys: simulation and experiment. Energy and Buildings, 32(1): 71-79. https://doi.org/10.1016/S0378-7788(99)00038-9

[8] Nouanégué, H.F., Alandji, L.R., Bilgen, E. (2008). Numerical study of solar-wind tower systems for ventilation of dwellings. Renewable Energy, 33(3): 434443. https://doi.org/10.1016/j.renene.2007.03.001

[9] Bassiouny, R., Koura, N.S. (2008). An analytical and numerical study of solar chimney use for room natural ventilation. Energy and Buildings, 40(5): 865-873. https://doi.org/10.1016/j.enbuild.2007.06.005

[10] Haghighi, A.P., Maerefat, M. (2014). Solar ventilation and heating of buildings in sunny winter days using solar chimney. Sustainable Cities and Society, 10: 72-79. https://doi.org/10.1016/j.scs.2013.05.003

[11] Imran, A.A., Jalil, J.M., Ahmed, S.T. (2015). Induced flow for ventilation and cooling by a solar chimney. Renewable Energy, 78: 236-244 https://doi.org/10.1016/j.renene.2015.01.019

[12] Hosseini, S.S., Ramiar, A., Ranjbar, A.A. (2017). Numerical investigation of rectangular fin geometry effect on solar chimney. Energy and Buildings, 155: 296307. https://doi.org/10.1016/j.enbuild.2017.09.017

[13] Khanal, R., Lei, C. (2014). An experimental investigation of an inclined passive wall solar chimney for natural ventilation. Solar Energy, 107: 461-474. https://doi.org/10.1016/j.solener.2014.05.032

[14] Ong, K.S., Chow, C.C. (2003). Performance of a solar chimney. Solar Energy, 74(1): 1-17. https://doi.org/10.1016/S0038-092X(03)00114-2

[15] Mathur, J., Bansal, N.K., Mathur, S., Jain, M. (2006). Experimental investigations on solar chimney for room ventilation. Solar Energy, 80(8): 927-935. https://doi.org/10.1016/j.solener.2005.08.008

[16] Dimoudi, A. (2009). Solar chimneys in buildings-The state of the art. Advances in Building Energy Research, 3(1): 21-44. https://doi.org/10.3763/aber.2009.0302

[17] Aboul Naga, M.M., Abdrabboh, S.N. (2000). Improving night ventilation into low-rise buildings in hot-arid climates exploring a combined wall-roof solar chimney. Renewable Energy, 19(1-2): 47-54. https://doi.org/10.1016/S0960-1481(99)00014-2

[18] Xu, J., Liu, W. (2013). Study on solar chimney used for room natural ventilation in Nanjing. Energy and Buildings, $\quad 66: \quad 467-469$. https://doi.org/10.1016/j.enbuild.2013.07.036

[19] Rabani, R., Faghih, A.K., Rabani, M., Rabani, M. (2014). Numerical simulation of an innovated building cooling system with combination of solar chimney and water spraying system. Heat and Mass Transfer, 50(11): 16091625. https://doi.org/10.1007/s00231-014-1366-5

[20] Li, J., Li, D. (2015). The study on numerical simulation of classrooms using hybrid ventilation under different solar chimney radiation. Procedia Engineering, 121: 1083-1088. https://doi.org/10.1016/j.proeng.2015.09.105

[21] Bansal, N.K., Mathur, R., Bhandari, M.S. (1994). A study of solar chimney assisted wind tower system for natural ventilation in buildings. Building and Environment, 29(4): 495-500. https://doi.org/10.1016/0360-1323(94)90008-6

[22] Sekki, T., Airaksinen, M., Saari, A. (2015). Impact of building usage and occupancy on energy consumption in Finnish daycare and school buildings. Energy and Buildings, 105: 247-257. https://doi.org/10.1016/j.enbuild.2015.07.036

[23] Mathur, J., Mathur, S. (2006). Summer-performance of inclined roof solar chimney for natural ventilation. Energy and Buildings, 38(10): 1156-1163. https://doi.org/10.1016/j.enbuild.2006.01.006

[24] Bassiouny, R., Korah, N.S. (2009). Effect of solar chimney inclination angle on space flow pattern and ventilation rate. Energy and Buildings, 41(2): 190-196. https://doi.org/10.1016/j.enbuild.2008.08.009

[25] Smith, J., Hinterberger, M., Schneider, C., Koehler, J. (2016). Energy savings and increased electric vehicle range through improved battery thermal management. Applied Thermal Engineering, 101: 647-656. https://doi.org/10.1016/j.applthermaleng.2015.12.034

[26] Ong, K.S. (2003). A mathematical model of a solar chimney. Renewable Energy, 28(7): 1047-1060. https://doi.org/10.1016/S0960-1481(02)00057-5 
[27] Mathur, J., Mathur, S. (2006). Summer-performance of inclined roof solar chimney for natural ventilation. Energy and Buildings, 38(10): 1156-1163. https://doi.org/10.1016/j.enbuild.2006.01.006

[28] Bansal, N.K., Mathur, J., Mathur, S., Jain, M. (2005). Modeling of window-sized solar chimneys for ventilation. Building and Environment, 40(10): 13021308. https://doi.org/10.1016/j.buildenv.2004.10.011

[29] Chantawong, P., Hirunlabh, J., Zeghmati, B., Khedari, J., Teekasap, S., Win, M.M. (2006). Investigation on thermal performance of glazed solar chimney walls. $\begin{array}{llll}\text { Solar } & \text { Energy, } & \text { 280(3): }\end{array}$ https://doi.org/10.1016/j.solener.2005.02.015

[30] Bacharoudis, E., Vrachopoulos, M.G., Koukou, M.K., Margaris, D., Filios, A.E., Mavrommatis, S.A. (2007). Study of the natural convection phenomena inside a wall solar chimney with one wall adiabatic and one wall under a heat flux. Applied Thermal Engineering, 27(13): 22662275 . https://doi.org/10.1016/j.applthermaleng.2007.01.021

[31] Miyazaki, T., Akisawa, A., Kashiwagi, T. (2006). The effects of solar chimneys on thermal load mitigation of office buildings under the Japanese climate. Renewable Energy, 31(7): 987-1010. https://doi.org/10.1016/j.renene.2005.05.003

[32] Nouanégué, H.F., Bilgen, E. (2009). Heat transfer by convection, conduction and radiation in solar chimney systems for ventilation of dwellings. International Journal of Heat and Fluid Flow, 30(1): 150-157. https://doi.org/10.1016/j.ijheatfluidflow.2008.08.006

\section{NOMENCLATURE}

$A$
$C_{d}$
$C_{P}$
$d$
$h$

Section $\left[\mathrm{m}^{2}\right]$

discharge coefficient $=0.57$

specific heat, $\mathrm{J} \mathrm{kg}^{-1} \mathrm{~K}^{-1}$

distance between wall and glazing, $\mathrm{m}$

convective exchange coefficient, $\mathrm{Wm}^{-2} \mathrm{~K}^{-1}$ incident solar radiation, $\mathrm{W} \mathrm{m}^{-2}$

thermal conductivity, $\mathrm{W} \mathrm{m}^{-1} \mathrm{~K}^{-1}$

length, $\mathrm{m}$

mass flow, $\mathrm{kg} \mathrm{s}^{-1}$

absorbed solar radiation, $\mathrm{W} \mathrm{m}^{-2}$

temperature, $\mathrm{K}$

Time [s]

absorbed heat flux density, $\mathrm{W} \mathrm{m}^{-2}$

overall exchange coefficient, $\mathrm{W} \cdot \mathrm{m}^{-2} \cdot \mathrm{K}^{-1}$

velocity, $\mathrm{m} \mathrm{s}^{-1}$

velocity at the exit $(\mathrm{m} / \mathrm{s})$

width of the air channel, $\mathrm{m}$

inner opening size, $\mathrm{m}$

$A C H \quad$ air changed per hour, $\mathrm{h}^{-1}$

$\mathrm{Nu} \quad$ number of Nusselt

$\mathrm{Pr} \quad$ number of Prandtl

Gr number of Grashof

\section{Greek symbols}

$\begin{array}{ll}\rho & \text { density, } \mathrm{kg} / \mathrm{m}^{3} \\ \varepsilon & \text { emissivity } \\ \alpha & \text { absorptivity } \\ \tau & \text { transmissivity } \\ \mu & \text { dynamic viscosity, } \mathrm{kg} \cdot \mathrm{m}^{-1} \cdot \mathrm{s}^{-1} \\ \sigma & \text { Stephan- Boltzmann constant, } \mathrm{W} / \mathrm{m}^{2} \cdot \mathrm{K}^{4}\end{array}$

\section{Subscripts}

$\begin{array}{ll}i & \text { admission } \\ o & \text { exit } \\ w & \text { inner wall of the absorber } \\ g & \text { glazing } \\ f & \text { fluid } \\ a & \text { ambience } \\ \text { ins } & \text { insulation wall } \\ m & \text { mean } \\ r & \text { room }\end{array}$

